\title{
Positivities of Globalization in the Domain of Developing the Human Resources
}

\author{
Dr. Hamzeh Ismaeil Ibrahim Abu Shari'ah ${ }^{1}$ \\ ${ }^{1}$ Associate Professor/ Faculty of Arts \& Sciences, The World Islamic Sciences \& Education University-Amman \\ - Jordan
}

Correspondence: Dr. Hamzeh Ismaeil Ibrahim Abu Shari'ah, Associate Professor/ Faculty of Arts \& Sciences, The World Islamic Sciences \& Education University-Amman - Jordan

Received: June 2, 2020

Accepted: July 7, 2020

Online Published: July 9, 2020

doi:10.5539/mas.v14n8p35

URL: https://doi.org/10.5539/mas.v14n8p35

\begin{abstract}
This study aimed at clearing what globalization left of positive effects in the domain of human resources, the study had been performed on the hypothesis meaning: (that there is a correlating relationship with a positive dimension between the globalization and the human resources manifest in one of them increase of awareness and improving performance), but the problem of the study had possessed an axis in the following questions: (What are the positive effects of globalization in the domain of human resources?), to be asserted of the hypothesis correctness and answering its axial question, so we had employed the analytical descriptive method. The study had deduced the correctness of the hypothesis, and made us reach numerous results, the most significant of them: is that globalization observed rights of the human resources and protected them from violations, shared in increasing awareness of the human resources in plenty of things which were absent from them, also pushed the governments to concern and promote with performing the human resources, and these results obliged numerous recommendations, the most significant of them: necessity of the states doing the enlargement of positivisms of globalization in the domain of human resources, and belittling their negativisms through studied programs.
\end{abstract}

Keywords: positivisms, development, globalization, human resources

\section{Introduction}

The term of globalization attracts more discussion a day after another and turns round its dialectic for what this term has of direct impact practiced power to dominate the life of humans, since the first moment taken by media means at their different types, and associations of western minds-making in raising and marketing them by laymen and cultured people quality, this term that comes as an extension of the famous Canadian Communications Scientist (Marshall McLuhan), performed on the basis of transforming the world into a cosmic village, or one world, which calls for globalization and welcomes it considering it allows the people with an appearance from large windows on cultures of each other, and this leads to advancement of peoples and increasing their awareness, and from them who views that globalization is nothing but a cultural invasion, a replacement of the colonial invasion, that renewed its garment and wore the cloak of culture instead of colonialism that people abhorred its objectives, and in this trend we will entrust the significance of globalization positivisms in the domain of human resources, considering that many people hated them.

\section{Significance of Study}

Significance of study springs from the drives, that pushe the researchers to tackle subjects that preoccupy their thinking, and in the domain of globalization we find that the follower of writings by people preoccupied in its subject, he finds the image amazing by the positive raising of this global trend, also it is full of the negative raising, and by the same amazing image and from the meaningful saying in this trend that literatures of globalization concentrated on the negative look more than on the positive look, because this is sent from the start of non-satisfaction about the western expansion that is wanted to be a replacement of what some local, or regional movements call for to the degree of return to call for a contradictory globalization (Al-Namlah, 2009: 23), so at the Arab level fifteen writers in the globalization symposium submitted their shares in the negative look towards globalization, inspite of what some deductions showed from the technique of self-whipping (Abdel Mu'ti, 1999: 392). 
Leaning on what preceded the significance of study in tackling the positivisms of globalization springs from its being uncovering the other face of globalization in what concerns developing the Arab Human Resources, for the sake of pouring our research shaves this time in the basket of positivisms and not in the basket of globalization negativisms, because variation is beneficial and there is nothing negative at all. So the significance of this study in the domain of human resources, springs from being aware of positivisms of globalization to enlarge them in the image that promotes with the human resources to a higher degree in the scale of luxuries, or at least to join the other human resources in the developed states (look the figure 1) on the following page.

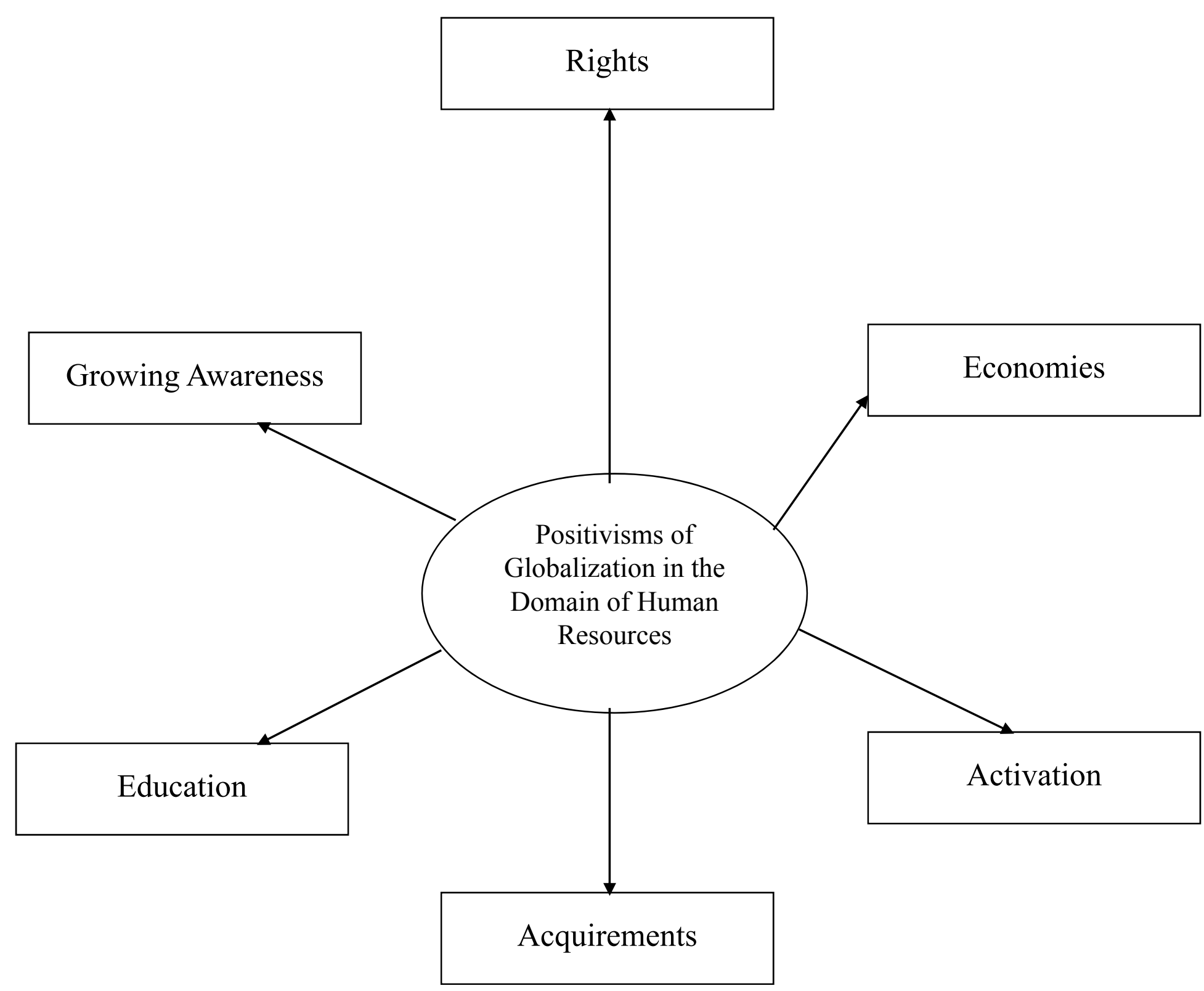

Figure 1. Globalization Positivisms in the Domain of Developing the Human Resources 


\section{Hypothesis of Study}

The study is performed on a hypothesis informing: (that there is a correlative relationship between globalization and improving the performance of the human resources, and increasing their awareness, in many matters that are in the verdict of absent from that, that is through what are sent of positivisms about this global phenomenon).

\section{Problem of Study}

The problem of study conceals in the extent of what globalization leaves of positivisms reflected in turn on performance of human resources, to be able to dig their way in a better form in the domain of man service, and the problem of study has its axis in the following axial question: what are the positive impacts that are left by globalization in the domain of developing the human resources? And branches from this question numerous subsidiary questions, they are:

1. What is globalization?

2. What about the rights of the human resources in the shadow of the phenomenon of globalization?

3. What is achieved by the human resources in the economic side in time of globalization?

4. What are the effects of globalization in what concerns the development of human resources awareness?

5. Does globalization have a role in educating the human resources?

6. What is the role of globalization from part of activating the human resources?

7. What are the acquirements that the human resources obtain from the phenomenon of globalization?

\section{Objectives of Study}

This study is concerned with achieving the following objectives:

1. Recognizing globalization?

2. Clearing rights of the human resources in the shadow of the phenomenon of globalization.

3. Presentation of what the human resources achieved economically in time of globalization.

4. Getting acquainted with impacts of globalization in what is related with developing awareness of the human resources.

5. Illustrating the role of globalization in educating the human resources.

6. Pin-pointing the role of globalization from the side of activating the human resources.

7. Getting acquainted with the acquirement that the human resources obtain from the phenomenon of globalization.

\section{Methodology of Study}

This study depends the analytical descriptive method, being the method that explains what is being obtained of information concerns the subject of study.

\section{Previous Studies}

There are numerous studies that tackled globalization from all faces, but what can be indicated, and what we have got and relates with what we are discussing:

- Amin study (1998) entitled "Globalization and the Modern Technological Community". The study aimed at pin-pointing what globalization left impacts on the communities that depended technology in all domains. And the researcher deduced numerous results, the most important of them: is that globalization has impact led technological communities to overstep time to advance for years.

- Thabet study (1999) entitled "Globalization and the Future Alternatives". The study aimed at clearing what results from globalization of impacts in the future on communities from part that they are pushed to explain patterns of their life and replace them with different new patterns.

- Al-Ziyyadi study (2004) entitled "Globalization and its Impacts on the Islamic World". The study aimed at clearing what globalization leaves of impacts on the community in general, and were performed on the hypothesis that globalization has negative impacts on and others positive. There searcher deduced that negativisms of globalization surpassed its positivisms.

- Donya study (2004) entitled "Globalization and Method of Prevention from its Dangers". The study aimed at clearing what can be taken of anticipating steps to belittling the negativisms of 
globalization at an extent. The researcher deduced through his study numerous deductions, the most important of which: that globalization has dangers, so in case of inattention means glorifying production and increasing it at states exporting globalization in return for belittling production and non-increasing it in the receiving - states of globalization.

- Al-Rifai \& et al (2005) entitled "Globalization and some Social Economic Effects Resulting From It", where the study was performed on its axial problematic question, what are the social and economic impacts resulting from the phenomenon of globalization, the researcher had deduced through his study, that globalization is a phenomenon with dangers surpass positivisms on the community and the state, that is because of individuality of the United States of America in leading the new world, being does not promote except with what serves its objectives in the world.

This study differs from its precedent studies being following the positive side of globalization, and observing the extent of benefitting from it in the domain of glorifying the role of human resources in the states that are dominated by impact of globalization, to push these human resources to improve their performance in the shadow of the worldly race in the domain of production and expression. And in the show of our answering the questions of study, so we show them as follows:

\subsection{Firstly: the Concept of Globalization}

It is looked at globalization as an aspiration and economic, political, technological, civilized, cultural and educational trend, in which limits among states of the North and the South and among civilizations each other, and in which nations, peoples, states, and individuals constantly and great haste communicate, and emerge from their mutual dependence among them and in all domains, like the mutual dependence in the capital investments, goods, services, ideas, concepts, cultures, and persons (Al-Hazaimah, 2010), and the meaning of this is that globalization is nothing, but is a phenomenon, or a complicated movement being with different dimensions..economic political, social, civilized, cultural, technological and else, produced by circumstances of the contemporary world and affect the life of individuals, peoples' communities, and the states with very deep impacts, but in the domain of defining the globalization it had been defined by numerous definitions, of them: that globalization is nothing but imposing the Western model with all its different colors on the states of the world and its peoples, (Al-Hazaimah, 2010: 307), and from an economic point of view it had been defined as "A Transformation towards the economy of the market in front of the movement of transferring the capital and liberation of the world trade" (O'lwan, 1998: 4-5), and from the political side, globalization means: "spreading and generalization of liberal democracy concepts, and what follows of rejection and ending authority and comprehensiveness in government, and adapting the political multitudes and commitment to respecting human rights" (Yasin, 1998: 12), but from the cultural side means that it is "Generalizing values, principles and the standards of the Western culture and in its beginning is the American model, and making it a cosmic model it should be adopted and initiated" (Al-Hazaimah \& et al, 2013: 107), from what preceded we view that globalization is "A cosmic phenomenon works on spreading values and new principles affect the human resources negatively and positively, and the states make doing all what limits negativisms of this phenomenon and enlarging its positivisms to move forward in the path of promotion and advancement and to converse its identity from loss and melting in a crucible of states civilization that made found globalization".

And after ending acknowledgement of globalization we have to present views of plenty of writers about this global phenomenon and these stands had been confined in the frame of a group it is (Sager, 1998: 210):

1. There are who view that globalization is a human evil and its results are negative, because it had been designed by the capitalist colonial states, particularly to achieve their goals and harvest acquirements, by that they make barriers rather empower other states from achieving any acquirement.

2. There is a constant group views globalization that it is a cosmic phenomenon cannot be confronted, therefore it should not be concerned to it waiting its real results and after it can be behaved in accordance with what it confirmed of results.

3. There is a group that views globalization as far as it has of negative results bear in its folds some positive results in case of dealing with it by a limited method done by understanding the phenomenon, so as to direct the work at that time by the form that enlarges results for the interest of human resources that are the pillar of the state and the capital of its wealth. By this the study is concerned with following up such positivisms, that are considered discharges of the global phenomenon. 


\subsection{Secondly: Globalization and Human Resources Rights}

The amazing development in communication technology revolution of informatics and technicalities either in new transfer including news of violations, or reaching the normal citizen across the facsimile and the Internet beside the other different means of media that made people all of them in our planet, they live in a vision and hearing from each other, and so it had not been possible to conceal the violations that are attached with human rights, here and there, in addition to the nutrition of human rights organizations in the developing states with the news and activating them, the thing that is reflected all in its role to notify the human resources with their rights and the necessity of maintaining their freedoms (Al-Fatlawi, 2009: 32), and the thing that made that easy are operations of communication across means of communication at their types became easy and accessible today, and in turn perform them positive reflections in the domain of developing human resources, and to more of advancement in the domain of awareness of basic freedoms for man (Al-Fatlawi, 2009: 27). And we can raise what elevates the level of human on rights in the shadow of globalization, where governments headed by the political elites, push to rouse and raise the affair of human resources through numerous sides, and we indicate to two sides, of them:

\subsubsection{Right of Labor}

Constitutions of states guarantee the right of labor and education for peoples, where legislations guarantee labor as for every citizen able has the right in the productive labor that enables him to earn his living, and live a good life, and the states have to make ready opportunities about laying methods, plans and developing programs, to guarantee the right of labor for all to whom are in the age of labor, and in case non-observing the right of labor, so unemployment leads to grumbling and development to demonstration and staying in strikes, so they are transferred by different means of communication, the audible, readable, and visible, chaos is common, and the political atmosphere in the state corrupts, so the states are desirous to make its fame remain high in observing the right labor and wages (Abdul Aziz et al, 2011: 57-74). And if observing had been done, the political system enjoys stability and the human resources are encircled round it, support and empower its props.

\subsubsection{Wages}

Globalization pushed in the direction of forcing governments to walk with interests of human resources in the domain of labor to lay a specified system related with wages, at a form guarantees satisfying the basic needs of the worker- organizing techniques of protecting them and increases emergent on them, within the basis of the only one wage of the one labor without differentiation, as pushed the governments to connect the wage with production at many cases and on the basis of the worker's obtaining the lowest limit of wage, if production increased more than the determined average workers were granted on additional wage more than the productive increase, and this in turn there is a case of competition among workers, the thing that leads to increase production, that flows plenty of benefit for the association (Al-Namlah, 2009: 90-134).

From the results of the global movement in the domain of wages that they limited the daily working hours and what it added to the limited daily hours, also globalization made the right for the human resources in receiving money for the caused accidents by labor either what is paid to hospitals, or what is added to the pension salary because of disease (Al-Hazaimeh, 2010: 35).

And in cases different from that, lead to workers grumbling and perhaps to disorders so the economic wheal in the country, the thing that affects the track of the government, being the labor movement will raise slogans hostile to the governments and accuses the country with non-observing human rights, and else of this respect and these news flowed and be received by means of communications the matter that urges to circulate un-proper rumors.

\subsubsection{Thirdly: Globalization and Economies of Human Resources}

The different economic policies adopted by the companies crossing the nationalities, western establishment, breeding, and management, and through means of communication that came with the global phenomenon that expresses a global perception too, make man search for labor opportunities through these means, and many youths join the labor market there, and this leads to limit aggravating problem of unemployment in many of the negative sides in life of peoples like thefts and robbery.....etc., and this in itself is considered a step forward in developing the human resources where the community lives in calmness and stability, and in such environments, in them man does be active without fear, or horror, add that this acquirement leads to opulence that, in turn leads to generate welfare, and they are both two factors of human resources factors if were properly used (Abu Salha, 2011: 113-114). Joiners of external labor market acquire qualitative experience, and in case of return to their country, unemployment in troops of human resources decrease, because of qualification and experience acquired 
from the external labor market, and in case of their transference from a place of work into another in the external labor market we find the opportunities open in front of them in finding another labor, as rarely you find among troops of qualified classes from employees, unemployed from work in general (Shirbinbergh, 2002: 18).

This makes us move to say: means of communication, that accompanied globalization, and it is a means of its promotion means, had opened, no doubt positive windows for the human resources, so as to acquire labor opportunities and limit the unemployment at their country, and this is reflected on the political regime with positive effects, where there is no opportunity for riots, disturbances and demonstration against this regime, being all are preoccupied with their labors, that spring them what satisfies their needs and returns them with benefit and perhaps increases, add that the financial treasury of the regime supports with money that makes the currency stability distinctive mark for that regime.

\subsubsection{Fourthly: Globalization and Development of the Human Resources Awareness}

From positivisms of globalization in the domain of developing the human resources, that comes through the mutual relations, that come because of the increase of averages of information, ideas, different patterns of behavior and values, for globalization takes a role flows in transforming the closed communities into open ones, for the open community inclines to be more active and vital than the closed community, and at that time this community shows to be more ready for renewal and innovation (Jabbar, 2017: 20-52), add that from the most significant accomplishments of the age of globalization is appearance of the civil community in its different organizations, that took on their shoulder performing the role of the mediator between the state and the people in an attempt to increase awareness of the public with their rights, and then working on keeping them and enhance their abilities on participation and protecting the individual freedoms (Rabe', 2000: 354).

The age in which we live is the age of globalization if we wanted or rejected, and no choice except it, as a result of the direct impact on peoples, that is imposed by means of media and contemporary technology, so the idea of globalization is not a hundred percent rejected, because it responses to high human values, in accordance with the basic goal and the positive concept, or the announced by globalization, as seen in the globalization a civilized, cultural and ethical project embodies the ambition of the contemporary peoples towards integration, solidarity and development (Nassar, 2015: 2-8).

Peoples and this case feel with their existence in case of attaining that integration, solidarity and development, so peoples seek attaining that stage armed with a great amount of awareness and knowledge, for the sake of reaching that degree of attainment. Add that globalization led to appearance of institutional work, that is not expected to master steadfastness except by awareness and knowledge, that the human resources have to be armed with, and this is evident through crystallizing constituents and props of the main associations and their role in the community, and that the human resources have to manage these associations with awareness and ability, and this refers on the political system with many positive effects, the advancement with the human resources by the arm of knowledge to attain ambitions level of these resources, no doubt their satisfaction about the system to which the course of knowledge to reach their goals was opened.

\subsubsection{Fifthly: Globalization and Educating the Human Resources}

The astronautics and technicalities of information that accompanied the phenomenon of globalization, that are considered from means of their spread, and they are called in the world of today and in all countries, they have their horrible impact in developing the system of open learning and on line learning, and reach with the learning services to millions of people and in all parts of the world to those who wish in learning, wherever they were and whatever their homelands went away from sources of classical education in their country. The astronautics and the Internet had overstepped the possibilities of learning into behind the limits of the one state, and allowed the citizens of the world obtain opportunities of education and obtaining developed learning services about foreign sources go away thousands of miles from their residence, and the concept of education all along life is the prevalence in most of the states, so the canals of astronautics and systems of direct transmission, are now considered a basic source for information and the mutual cultural impact among the states all over the world, where that is considered a basic factor in melting the different cultures in one culture it is the culture of globalization (Kortell, 2012: 14). The fraction of nations and peoples by different means of communication and means of media lead to high urgent need in educating the human resources and developing them, because the increase of communication between peoples of developing states and the developed states encourages on acquiring the different cognitions, in one of them by the completion of the developing states members, or undeveloped their study in the developed states, so they copy that advancing model in their countries after the return to their country, so we see plenty of members of the developing states by Internet submit applications to join universities of the developed states, as missioned on behalf of those states and on their expense, and this will 
not be done without the means of technology that prevail in the age of globalization, and this, in turn, refers on the political regime with many positivisms, of them that the system works for the interest of the human resources, and does not cross with their interests.

\subsubsection{Sixthly: Globalization and Activating the Human Resources}

Activating the human resources comes through pushing governments and political regimes to care for the human resources and pushing them forward from the side of improving performance for these resources, so governments had taken the trade of other governments that raise the levels of the human resources, so they direct to establish the governmental training centers, and allowed establishing the private centers in the trading foundations and industry, including the technical institutes and the applied colleges; of technical, health, agricultural and informational and chase of new training in the developed states and working on the settlement of the new of them (Al-Namlah, 2009: 59). Also governments sought refuge to enlarge accomplishments of the training centers to the mutual cooperation in the domain of training and the industrial rooms outside, where governments recommend through their embassies abroad and through the cultural attaches and economists to conclude agreements and treaties that serve this goal, in order the affair of these treaties and agreements is the exchange of experiences among the states, the thing that leads to raise the affair of human resources performance, and the governments had sought to motivate the human resources and activate them through connecting employment with obligation of overstepping a number of qualifying courses, for acceptance in labor market, and choice of the upper and the best from the competitors, and that to create a case of competition in obtainment and accomplishment, because whenever the qualification increased it leads to convince employers and companies from trending to the worker citizen and choosing him to organize the group of workers who work in these companies, being achieved advancement in the domain of qualification, training and commitment with ethics of work in (Al-Namlah, 2009: 61-62).

Governments have to response to activating demands of the human resources till they do not remain dull, and leave from competition, being unable for that, and whenever governments were working in this direction wherever satisfaction appeared evident among troops of the human resources, and this refers on the political regime with positivisms, for example whenever the state promoted with the level of human resources and in turn comes with a financial return to the treasury of the state, and this is what the status want.

\subsubsection{Seventhly: Globalization and Acquirement of the Human Resources}

The human resources had acquired numerous political matters in the previous studies found approaching them restricted, as a result of the valor of the political regimes, and we can raise these political acquirements by the following (Jouher, 2018: 103-106):

\section{Bravery}

Globalization had pushed peoples and individuals to bravery in saying the right, this is that was absent since a long time, and bravery manifests in what was said by the public, that shouted with to dethrone governments and departure of leaders, and indication by names without reservation to the corrupts, even if they were with authority owners, and calling with obligation for their trial even if they were from the close companions to the highest authority in the country, so the restricted became easy and accessible, and from the aspects of bravery at the public is the challenge of prisons and arresting places, and said what they had not said in the past, where the spirit of challenge crept from one people into another, meaning that the matter was not confined to a people of a state itself, no sooner than the matter crawled in a state till the other state quivered, and the phenomenon crept in it wanted or rejected, except the states that formerly had given a little bit of freedom to its people, it had been harmed at a lighter form than other states (Al-Rifai, 2005: 203-207).

\section{Drive Towards Change}

Globalization pushed the crowds to occur lets change in the political approach, and it is performed on the necessity of alternating authority, after some leaders had shown the intention of bequeathing the government and remain in the government without making room for the others in participation, and this is what called the public for calling to non-confining authority to leadership installed itself in accordance with a constitution formed all by itself to conserve authority forever as it was calling, the social media had its great role in blazing feelings of the human resources for the group participation in adopting one objective to meet on, and it had that, so some leaderships concealed and others departed and leaderships were killed, thought that the public cannot do that (Samha, 2005). 


\section{Weakening the Tyrant Regimes}

Globalization is considered a means to hasten the scientific democratic development, and so the public did not accept the tyrant regimes that burdened the shoulders of peoples, and this comes through the globalization opening new un-terminal cognitive horizons to trial the tyrant regimes, these horizons had never to open their gates without the related side with the scientific and informatics that was made available by the modern means of communication at their different types, so those regimes took comprehensive reformation processes till not to be burned by fire that caught other regimes, they were burned by the fire of obligatory alternation (Samha, 2005).

\section{Conclusion}

The study had come asserting the correctness of the hypothesis upon which it was performed: it is "there is a correlating relationship between the globalization and improving the performance of the human resources and increasing their human resources in plenty of matters, that is from the results of positivisms that are emerged through this worldly phenomenon", also answered the axial question round which the problem of study had an axis, meaning: (What is the extent of what globalization leaves of positive effects reflected in turn on the performance of human resources", and the study had deduced numerous results; they are:

1. Globalization observed rights of the human resources and conserved them through enlightening the human with his rights, and what guarantees these rights from loss, or aggressing on them.

2. Globalization opened horizons for work broke the sharpness of unemployment, because of globalization means that opened the human resources horizons of work.

3. Globalization pushed the human resources in the country state to get benefit from the culture of the human resources in many of the world countries, the thing that led to increases innovations at work, and stabilize the professional atmospheres at the human resources and enhancing them.

4. The globalization was an instrument of pushing the governments to promote the human resources as improving performance in one of them it is establishing centers for training and developing of these resources.

States have to do all what is possible to decrease the negative impacts and enlarging positivisms that emerged because of this phenomenon, that is for the sake of conserving their values, beliefs and customs, that go with their environmental nature and religious privacy altogether.

\section{References}

Amin, Jalal. (1998). Globalization, identity and the modern technological community. Journal of Arab Future, Beirut, (234), 58-69.

Abdul Aziz et al. (2011). Economic globalization and its effects on the Arab Countries. Journal of Administration and Economics, Al-Mustansyriah Univesity, 86, 61-84.

Abu Salha \& Ashraf Ghaleb. (2011). The Political Impact of Globalization on the Arab World (1991-2011). M.S., Middle East University, Amman, Jordan.

Abdel Muti \& Abdel Baset. (1999). Globalization and the Societal Transformation in the Arab World Cairo: Madboli Library.

Al-Fatlawi, Suheil. (2009). Globalization and its Impacts in the Arab World. Amman: (Darel Thaqafa) Culture House for Publication and Distribution

Al-Hazaimah \& Mohammad Awad. (2010). International Issues, Amman, Dar Al-Hamed.

Al-Hazaimeh \& Mohammad Awad. (2013). Islam and Issues of the Age, Amwaj for Publication and Distribution. Amman, Jordan.

Al-Rifai \& Abdul Hadi. (2005). Globalization and Some Social Economic Effects Resulting from It. Tishreen University Journal for Studies and Scientific Research-Economic and Legal Science Series, 27(1), 2005.

Al-Namlah \& Ali Bin Ibrahim. (2009). Globalization and Preparing the Human Resources in the Arab Gulf Region. Riyadh: Al-Ibeikan Library.

Al-Ziyyadi \& Mohammad Fath Allah. (2004). Globalization and its Impactson the Islamic World. Journal of the Islamic Jurisprudent Assembly, 14(4), 154-176.

Donya, Shawqi. (2004). Globalization and Method of Prevention from its Dangers on the Islamic Nation. Journal, Journal of Islamic Jurisprudent Assembly, (14). 
Jabbar, Ebtehal Kadhum. (2017). Globalization and its impact on religious education for youth (empirical study in Al-Diwaneyah). University of Al-Qadisiya College of Arts (Department of Sociology/ Higher Studies), Iraq.

Jouher, Belhanafi. (2018). Human Rights Between Universality and Globalization. Journal of Political Science and Law, 10(2), 95-108.

Kortell, Fareed. (2012). Strategies of Managing the Human Resources in the Shadow of Globalization Together with Indication to the Case of the Arab Countries. the International Scientific Conference Globalization Management in the Age of Knowledge (De. 15-17, 2018), Al-Jinan University, Tripoli, Lebanon.

Nassar, Jamal. (2015). The Cultural Identity and Challenges of Globalization. Al-Jazeerah Center for Studies, January 28, 2015.

Olwan, Hasan. (1998). Globalization and the Arab Culture, The Fourth Scientific Conference (May $4^{\text {th }}-9^{\text {th }}$, 1998) Amman, Philadelphia University.

Rabe, Mohammed. (2000). Industry of Arab Future in the Historical Development from the Tribe to the State. Beirut, Bhasoon Association.

Samha, Omar. (2005). Cultural Globalization and the Arab Political Culture: Democratic Reform Programs and Participatory Arab Political Culture. M.S., An-Najah National University, Nablus, Palestine.

Sager, Turki. (1998). The Arab Media and Challenges of Globalization. Damascus: Ministry of Culture.

Shirbinbergh, Norman. (2002). Opportunity of Globalization: Powerful People will increase power. Translated by Hussein Imran, Riyadh, Al-Ibeikan Library.

Thabet, Ahmad. (1999). Globalization and the Future Alternatives. Journal of Arab Future (Beitur), 240.

Thabet, Ahmad (2003). Globalization and its Precariousnesses on the Arab World. Series of Arab Future Books (24), Center for Arab Unity Studies, Beirut, January, 2003.

Yasin, Al-Sayed. (1998). In the Concept of Globalization. Journal of the Arab Future - Beirut, 228.

\section{Copyrights}

Copyright for this article is retained by the author(s), with first publication rights granted to the journal.

This is an open-access article distributed under the terms and conditions of the Creative Commons Attribution license (http://creativecommons.org/licenses/by/3.0/). 